Work, employment and society

\title{
Transient craft: reclaiming the contemporary craft worker
}

(C) The Author(s) 2014

Reprints and permissions: sagepub.co.uk/journalsPermissions.nav DOI: 10.1 177/09500।70I4535834 wes.sagepub.com

@SAGE

\section{Helen Holmes}

University of Sheffield, UK

\begin{abstract}
This article joins with Richard Sennett's reclamation of the craft worker, but also extends it. Through a focus on craft as experience and repetitive practice, Sennett reveals how craft is a key facet of several contemporary professions. Using the example of hairdressing, this article moves beyond Sennett's conclusions, illuminating how craft is at work within female-dominated service professions. The article adds to the growing body of literature on hairdressing, recognizing that while this literature involves body and emotion work, such growth has been at the exclusion of the craft components of the work. More broadly, the article argues that the craft of service work is obscured by the intangibility of the materials produced and the practices performed, thus limiting the value of such work.
\end{abstract}

\section{Keywords}

contemporary employment, craft, craft practice, craft worker, hairdressing, service work, skill, tools

\section{Introduction}

Craft is an elusive term, its credentials fervently debated. The ambiguity of 'craft' as a concept and its opposition to 'art' has long been a topic of academic discussion (Attfield, 2000; Becker, 1978; Fariello and Owen, 2005). More recently, studies have focused on a resurgence in craft production and the growing number of contemporary craft communities (Greenhalgh, 2002; Levine and Heimerl, 2008; Minahan and Wolfram-Cox, 2007). The DIY craft consumer has become a central figure (Campbell, 2005), operating at the blurred boundaries of amateur versus professional production of female-dominated type crafts, such as knitting, jewellery making and clothing production.

While this renewed interest in craft activity goes some way in illuminating contemporary craft work, its DIY focus clearly separates craft activities from mainstream

\footnotetext{
Corresponding author:

Helen Holmes, University of Sheffield, Room E49, Hicks Building, Sheffield, S3 7RH, UK.

Email: H.Holmes@shef.ac.uk
} 
employment sectors. In fact, rarely does craft feature in discussions around contemporary employment, where the focus remains on 'skill'. Debates on skills and the nature of skill within employment have been high on the academic agenda since Braverman's (1974) thesis on the deskilling of the labour force. Given the rapid growth of the service sector over the last 30 years it is no surprise that such debates have concentrated specifically on service work skills. While there have been those who have argued that service work is routinized and scripted, there are those who recognize that service work involves worker autonomy, creativity and particular skills. Specifically, these skills have been identified in feminized forms of service work involving emotional labour (Bolton, 2009), aesthetic labour (Witz et al., 2003) and body work (LeeTreweek, 1997; Twigg, 2000). Nevertheless, some scholars argue that there has been an overemphasis on the skills of emotion work in the service sector at the expense of other skills. As Hampson and Junor (2005: 177) stress, 'service work comprises intellectual and emotional labour.' Indeed, they advocate that to really draw out the 'intangible' and often 'invisible' skills of service work requires 'thick accounts' (2005: 171) of the activities taking place.

Richard Sennett's The Craftsman (2008) uses such an approach to draw out the skills of contemporary employment. Focusing upon the practices of work, Sennett illuminates how craft skills - skills which are learnt by experience, through repetition and practice - are at work within contemporary forms of employment. This interest in practice forms part of a wider academic enthusiasm for practice-based accounts and a desire to understand the choreographies of everyday life (Reckwitz, 2002; Schatzki, 2002; Shove, 2003). However, as this article explores, Sennett's account has limitations, not least in the view that craft remains peripheral in the female service sector. What is more and as this article develops, for Sennett craft always produces a stabilized product. Thus, the materially intangible, the transient and the temporary, such as is the nature of most service work, remains excluded.

This article puts service sector craft at the heart of its argument. By extending Sennett's practice-based approach to employment, it opens up craft practice to include the production of transient, unstable and intangible objects produced in female-dominated service sector work. Hairdressing is an ideal vehicle with which to explore the transient notion of craft within female-dominated service work. While the hairdresser adheres to Sennett's historical craft model through various characteristics of their profession, such as training, trust, a hierarchical structure and use of tools, its crafting of the transient and unstable is what sets it apart. By responding to Hampson and Junor's (2005: 171) request to use 'fine-grained observation' to unpack the all too often 'invisible' (2005: 167) and, thus, undervalued skills of service-based roles, this article argues that some forms of service work require highly skilled craft labour and, correspondingly, should be recognized and remunerated as such.

This article is divided into four sections. Following a methodological discussion, it begins by exploring Richard Sennett's reclamation of the craft worker and his focus upon the importance of practice and experience in skilled work. In doing so, it also addresses the limitations in Sennett's account. Secondly, the article positions itself within the contemporary service sector literature. In the third section the discussion centres upon the hairdresser and hairdressing as a form of skilled service sector craft work. The article 
concludes by arguing that both the skills and products of service work are rendered invisible because of their intangibility.

\section{Methodology}

The hairdressing case study used within this article is based on 12 months conducting participant observation research while working in a hair salon. The salon, which will be referred to throughout by the pseudonym 'Kirby's', is an independent salon based in the north-west of England. At the time of the research the salon employed 13 members of staff, all but one of whom were female. Similarly, the clientele were predominantly female. My role within the salon was as a voluntary, unpaid salon junior. This would involve performing typical junior type tasks, such as sweeping up hair, making coffee, washing hair, answering the phone and cleaning. The staff and customers were made aware of my ethnographic research agenda. During my time at Kirby's I kept a field diary, recording daily events and conversations. These were corroborated by my use of visual methodologies. Using photographs and video, I recorded some of the key hair practices which took place in the salon. My aim was to capture the narratives of practice and their embodied, lived experience (Holliday, 2001; O'Connor, 2007) through visual sequences of particular chronologies (Pink, 2001).

Towards the end of my time in the salon, I had established good relationships with the staff and clients and was able to arrange ten focus groups. This included nine focus groups of five to 10 clients and friends of clients (all female, bar one mixed focus group) about their hair care experiences and one focus group with the stylists. Following this, 10 one-to-one interviews with one person from each focus group were conducted to explore the key themes which had emerged from my research. The eldest participant was in their $80 \mathrm{~s}$ and the youngest in their 20s. Following transcription, data from interviews and focus groups, along with my field notes, were thematically coded and analysed using etic and emic codes. Similarly, the visual materials were analysed and themed, their content treated as 'realist representations of [the] specific interactions' of the salon (Pink, 2001: 135). In addition to this, I also independently undertook a six-month college course entitled 'Hair Care and Styling', a precursor for those wishing to study for the NVQ in hairdressing. This enabled me to gain an insight into the training hairdressers must undergo to become qualified and the continual focus upon practice within the industry.

\section{Richard Sennett's The Craftsman}

Richard Sennett's The Craftsman (2008) is crucial to debates about work, employment and society because it reclaims craft as a crucial element of contemporary labour. By focusing upon the practices of craft, Sennett's account reasserts the value of practical skilled work learnt primarily through experience. Such work adds to a succession of debates around the skilled or 'deskilled' workforce. As Lloyd and Payne (2009) conclude, the concept of skill is notoriously difficult to define. Recent literature illuminates a shift in the definition of skill from that of workplace and technical 'know-how' to a broader set of attributes including cognitive, communication and interactional skills (Clarke et al., 2013; Payne, 2009). Others draw on the socially constructed nature of 
skills (Toerien and Kitzinger, 2007) and how often skill is defined by the level of formal education it requires rather than technical ability or experience (Gatta et al., 2009).

For Sennett a skill is practical. It involves action, movement and the process of physically doing something to something with something/s. Therefore, Sennett's definition of skill is orientated towards the traditional classification of workplace 'know-how'. Sennett draws upon the notion of the 'craft worker', a primarily male figure, with specialized skills operating in many contemporary professions. He describes how the chef, architect and musician, among many others, are all craftsmen because of the "ten thousand hours of experience' (2008: 20) they have had perfecting their skills. Through what Sennett terms the 'rhythm of routine' (2008: 268), the worker becomes a 'craftsman'; repeating the skill over and over again until the 'practice beds in; making the skill one's own' (2008: 295). Thus, practical skills become crafts through experience, repetition and practice.

In Sennett's definition, anyone can be a craftsman (2008: 268); what separates the amateur from the professional, apprentice from master, is experience. The contemporary craft worker is identified within the practices of professions, such as architecture and engineering. Yet, it is also to be found in more manual and traditionally defined low skilled forms of labour, such as mining and bricklaying. Similarly, Sennett's study includes forms of work more readily identifiable with the craft tradition, such as piano making or pottery. It is the emphasis on practice which allows Sennett's craft worker to transcend conventional employment sectors, enabling roles traditionally defined as low skilled and menial to be seen in equivalent terms to professions considered highly skilled and complex.

A further feature of Sennett's craft skills is the workers' unique relationship with their tools. He describes the 'love' a craftsman has for his tools and how each is 'fit for purpose', 'knowing which act should be done with which thing' (2008: 195). Hence, craft involves a set of related skills enabled by various tools. Sennett develops this further, suggesting that the craft worker's tools become part of his body. He discusses how the craftsman's tools engaged in practice become an extension of the 'intelligent hand' - a coordination of hand, eye and brain (2008: 174). The craft worker is no longer self-aware, but becomes the thing they are working on and with. The joiner's hammer, the surgeon's scalpel, the conductor's baton all fuse with their owner through the repetition of practice. However, while Sennett's definition of craft skill is aligned with the traditional concept of skill as workplace 'know-how', his appraisal of the craft worker also recognizes the cognitive elements of the role. 'The good craftsman [...] uses solutions to uncover new territory; problem solving and problem finding' (2008: 11).

Sennett's focus upon the body engaged in practice sets his work apart from other craft studies. Many accounts of craft are object-centred, rather than practice or workerfocused, concentrating upon the object of craft as expressive of craft work or craft-inthe-making (Berry, 2009; Dormer, 1997; Terrio, 2000). However, Sennett is not so much interested in what the worker is creating, but more in the physical and embodied act of doing craft practice. Thus, through the contemporary craft worker engaged in practice, Sennett unites worker, tool and object. Hence, his account draws upon elements of employment studies, practice theory and material culture, to offer a unique approach to 
contemporary studies of labour and employment. Nevertheless, Sennett's work is not without limitations.

Like many craft studies, Sennett's work is bound by nostalgia for a romantic craft past. Indeed, there is a tension within the account between the craft opportunities offered by contemporary employment and Sennett's melancholy for the remnants of a particular craft history. Sennett laments how 'the head and the hand are not simply separated intellectually' in contemporary employment 'but also socially' (2008: 45). He discusses how the 'skills society is bulldozing the career path' whereby workers need to have a 'portfolio' of varying skills rather than pursue a single ability throughout their working histories (2008: 265). This Sennett pits against an ancient model of craft, complete with guild, workshop, master and apprentice. In this historical model the craftsman and his skills are respected and celebrated. Protected by the guild, Sennett describes how 'the repute of the truthful craftsman mattered politically as well as economically'; his skills were essential to medieval living (2008: 61). The workshop is portrayed as the epicentre of craft life, 'its foundation [...] authority, the knowledge it could pass on by imitation, ritual and surrogacy' (2008: 61). In this model, the master craftsman is a formidable, empowered figure and his craft a skill to be revered.

Yet, the account's juxtaposition of an ideal craft history, versus a problematic craft future, is further complicated by Sennett's attempts to overlay his historical craft framework upon a number of contemporary case studies. For example, Sennett compares the striving for excellence in the 18th-century violin workshop-cum-home of master craftsman Antonio Stradivari, to the pursuit for higher standards in the gargantuan structure of the NHS (2008: 243). Similarly, nurses are likened to medieval goldsmiths (2008: 62) and software writers to cooks (2008: 184). Doctors and bakers serve as illustrations of roles with master/apprentice type relationships (2008: 249); and contemporary professional communities are compared to ancient guilds through their need for accountability and standards (2008: 249). Thus, while Sennett appears to grieve for the vestiges of a romantic craft past, he likewise cannot move away from them, allowing them to permeate and, thus, restrict his exploration of the contemporary case studies he draws upon.

Sennett's nostalgia for a particular craft past is further perpetuated by his focus upon male-oriented professions. His examples of CAD engineers, architects and miners all reflect the archetypal male craftsman. There are a few references to female craft workers, including the scholar Erin O'Connor's foray into the craft of glass blowing (2008: 173), but the main focus of the account is upon the craftsman at work. Not only does this sustain Sennett's historical craft framework but it also limits the scope of professions Sennett draws upon. While Sennett's account reveals how skilled work is undertaken in roles deemed low skilled and thus less respected and valued, his model of craft makes little room for feminized forms of work and, in particular, service work. Although such forms of work (for example, nursing or cooking) are acknowledged as involving craft practice, they are not fully explored.

What is more, while Sennett's account allows us to use practice to think through craft, the focus for discussion tends to equate craft with the production of stable, durable products - a Barolo goblet or a Stradivari violin. Those professions which work with the intangible and/or transient and which do not produce tangible products are not closely examined. Yet, if craft is thought about as practice which is not simply stabilized by 
objects but can exist as practices alone, then the potential of craft work multiplies; this is the radical potential in Sennett's conceptualization. Through this concept, craft work can occur in activities which produce the transient, the temporary and even the intangible. In such a way, craft can be reclaimed as a means to think about service work.

\section{Contemporary service work}

The contemporary service sector covers a wide range of industries and occupations from retail, to hospitality, to health and care work. The argument that such work is deemed low skilled and also low paid is not new. Neither is the claim that such jobs are predominantly undertaken by women (see Halford et al., 1997; McDowell, 2009; McDowell and Pringle, 1992 to name but a few), or that this is because such service occupations generally require the 'soft' skills which women are stereotypically assumed to have. Indeed, essentialized attributes have been mapped into three, often intertwined, forms of labour which are seen to dominate service sector work - emotional labour, aesthetic labour and body work.

The first, emotional labour, is by far the most synonymous with academic debates around service sector work. Brought to life in Arlie Hochschild's (1983) The Managed Heart, emotional labour concerns how organizations attempt to manipulate and manage workers' feelings to create particular emotive states conducive to profit. Studies on emotional labour have included, among others, work on waitressing (Hall, 1993), care work (Lee-Treweek, 1997) and call centres (Callaghan and Thompson, 2002). The second, aesthetic labour, involves workers not only conducting emotional labour, but also embodying an organization's ethos through clothing, demeanour and appearance (Witz et al., 2003). Studies on aesthetic labour have looked at how flight attendants (Tyler and Abbott, 1998), shop workers (Pettinger, 2006) and models (Entwistle, 2002) all engage in aesthetical changes through their work. The third of the triplet is body work and this too is often intertwined with emotional labour. Body work is paid work performed upon the bodies of others. Originating from research on care work and nursing (see LeeTreweek, 1997; Twigg, 2000), it embodies feminized notions of caring and attending to the body. While the boundaries of what constitutes bodywork are somewhat fluid (see Twigg et al., 2011) the concept has been widened to include sex-work (Sanders, 2005), alternative therapy (Oerton, 2004) and beauty treatments (McDowell, 2009).

In recent work, there has been a strong emphasis on recognizing the skills involved in service labour. This is in response to accounts such as Braverman's (1974) deskilling thesis and also more recently work which suggests the 'McDonaldization' of service work, with service work becoming scripted, routine and depersonalized (Ritzer, 1996). Many scholars have challenged such assumptions, illustrating how service work involves skills which cannot be scripted or routinized (see Bolton, 2009; Gatta, 2009; Junor et al., 2009). Mary Gatta's (2009) study of restaurant workers discusses how conducting emotional labour can provide opportunities for a heightened sense of dignity. While Sharon Bolton and Carol Boyd's (2003) work on flight attendants discusses how workers interpret and manipulate managerially prescribed rules and find autonomy and humour through the work they conduct. Bolton and Boyd also argue that studies on service work need to move beyond emotional labour, as the sector is too complex to be defined by one concept. 
This idea is echoed by several studies which argue that there is too much emphasis on emotional work at the expense of other skills (Gatta et al., 2009; Hampson and Junor, 2005; Pettinger, 2006). Hampson and Junor (2005: 176), conclude that the skills performed through interactive service work involve 'a blend of emotional, cognitive, technical and time management skills, performed often at speed and at varying levels of complexity and autonomy'. As they go on to discuss in a later piece on care work (Hampson et al., 2009), often it is difficult to pin down service skills because they are often improvised and enacted. They are also automatic: skills which may be learnt through education but have to be practiced to ensure a smooth performance, such as using a hoist to lift a patient (2009: 205). Thus, they advocate the use of 'thick' descriptions to reveal these 'invisible', tacit and taken for granted skills. By combining and extending Richard Sennett's (2008) focus upon craft practice, along with Hampson and Junor's appeal to illuminate the invisible and intangible in service work through finegrained description, this article uses the example of the hairdresser to demonstrate how female-dominated service work can be skilled craft work and should be remunerated and respected as such.

\section{Hairdresser as craft worker}

Hairdressing is an industry which is typically understood as low skilled, service-based and female-dominated. Statistics have estimated that nearly 80 per cent of the UK hairdressing workforce is female (Habia, 2007). There is no doubt that hairdressers engage in various forms of skilled service labour, including emotion work, aesthetic labour and bodywork. Both Louise Kapp Howe (1977) and Debra Gimlin (1996), in their respective studies on hair salons, discuss how hair stylists are trained to act in a particular way - looking happy and listening to clients' problems: engaging in emotional labour. The aesthetic labour stylists undertake is discussed by Tracey Yeadon-Lee et al. (2011) in their study on the organization of work and customer service narratives within hair salons and also Jo Lindsay's (2004) work on gender and class in the lives of young hairdressers (see also Chugh and Hancock, 2009), while the body work element of hairdressing is recognized in Rachel Lara Cohen's work (2010) on hair stylist-client relations (see also Wolkowitz, 2002).

However, integrated with and complementing these varying forms of labour are practical skills which are tacit and intangible; skills which can only be revealed through an emphasis on practice and the actual 'doing' or crafting of hair. This is not to undermine the involvement of emotional work, aesthetic labour and body work in the hairdresser's crafting of hair. Indeed, as hairdressing is about 'paid work on the bodies of others' it could be argued that it is primarily a form of body work. Similarly, hairdressing requires emotional management, as was noted during the focus groups - hairdressers need to be personable and able to interact, as well as being able to work with hair. Likewise, the hairdressers at Kirby's often referred to their role as one of a 'therapist', listening to and placating clients. As Toerien and Kitzinger (2007) have shown, through their detailed work on the practice of threading in beauty salons, the interaction between therapist and client during the task is as essential as the actual action - the two are interwoven. Nevertheless, as I now show, the work of hairdressing benefits from being read through the lens of craft practice. 
Hairdressing as a craft is illuminated most powerfully through the rhythm of practice. As Sennett discusses (2008: 20), it takes 'ten thousand hours of experience' to master a craft and this is the case with the hairdresser. Investment in practice in the hair salon is illustrated most clearly through the salon's strict staff hierarchy. In Kirby's, the owner, Patricia, is at the top of the hierarchy. Beneath her is a team of experienced qualified stylists and below them a set of training juniors. Each is ranked by length of service; in other words, the number of hours of practice they have devoted to their craft. Such rankings are demonstrated and reinforced within the salon environment. For example, there is a clear delineation of roles. Tasks such as colouring, cutting and perming are the role of the qualified stylist; whereas jobs such as cleaning, hair washing and answering the phone belong primarily to the unqualified junior. Similarly, staff members' names appear in ranked order in the appointment book. In other words, the owner has the first column, the next longest serving member of staff the next column and so on.

Returning to Sennett's craft framework, this salon hierarchy is typical of the medieval craft workshop, with a master craftsman at the helm of the business, followed by varying ranks of apprentices (Camp, 1924). The stark difference in this case, is that all are predominantly female. To pass up through the ranks staff must serve their time and become qualified. Hence they must engage in hours and hours of practice. For the majority of hairdressers a key part of this practice involves completing a Level 2 National Vocational Training (NVQ) Award in Hairdressing. There are three Hairdressing NVQ Levels - Level 1 which is designed for juniors, teaching skills such as hair washing and drying; Level 2, the primary qualification, providing instruction in the main hairdressing skills of cutting, colouring and perming; and Level 3, the advanced qualification, awarded to those wanting to become salon managers and owners. In Kirby's to progress from junior to qualified stylist one must possess a Level 2 qualification. However, there are varying ways in which to achieve such qualifications. Some choose to enrol on a full-time college course, whereas others prefer to undertake a Modern Apprenticeship, which is predominantly salon-based with one day a week college attendance.

In Kirby's the Modern Apprenticeship is deemed a far superior way to achieve the qualification. During a focus group with the salon staff, Patricia, Kirby's owner, exclaimed that she 'would never employ anybody who had been to college full time' because their lack of skills was simply 'frightening'. Likewise, a stylist, Alana, described college as 'rubbish' and said she had learned everything she needed to know from working in the salon. While the term 'Modern Apprenticeship' has undeniable links to Sennett's historical craft framework of master and apprentice, the craft element in this is once again illuminated most powerfully by the focus upon practice. As both Patricia and Alana convey, the skills of the credible hair stylist are honed not by studying for the college course, but by the practice of physically 'doing' hair in the space of the salon; their skills are 'practically implanted' (Wacquant, 1995: 504). As Erin O'Connor (2007: 130) describes in her work on the corporeal practices of glass blowing:

The apprentice fashions her practice by making an implicit technique explicit, improving and realigning that technique with its intended purpose and allowing the revised technique to again recede into unconsciousness. 
Thus, the salon operates like the medieval craft workshop, as a place where apprentices learn their trade through practice and repetition.

This is in keeping with Sennett's theories that anyone can learn a craft through practice. Having a 'natural affinity' or 'flair' with hair was a subject regularly debated by salon staff and also mentioned by focus group participants. To the untrained eye, being able to transform a head of hair is often perceived as almost a magical act. Yet a seemingly 'natural affinity' with hair is once again down to practice.

You can teach pretty much anybody to cut hair ... Whether they will be any good at it is another thing. They have to practice. (Heather, former hairdresser, Focus Group 8)

Heather goes on to discuss how there are those who will pick it up straight away versus those who take much longer, but, as my discussions with Kirby's staff indicated, this difference is also down to practice. Indeed, many of the staff talked about having always been interested in hair and spending time when growing up plaiting their friends' hair or helping with their mother's colour. Thus, such craft skills are already ingrained through years of practice.

It is this constancy of practice, both in and away from the salon, which highlights another element of the hairdresser as craft worker. For Sennett there is little delineation between the craftsman at work and the craftsman at home; and certainly for the medieval craft worker home and work were often the same place (Blewett, 1983). Sennett evokes the notion that craft is an integral part of one's identity and this would certainly seem to be the case with hairdressing. The staff at Kirby's regularly do people's hair at home, out of working hours. Similarly, they often meet up in their free time to go shopping or for a drink, with conversations often turning to work and customers. Thus, they are always 'doing' hair in some sense - be it physically practising their skills or talking about it. As Geoffrey Crossick (1997: 5) describes, with reference to the historical artisan, 'artisanship was at the heart of one's social being and personality'; and so hairdressing is 'a core element of identity' for the contemporary hairdresser/craft worker (Lindsay, 2004: 266).

Tools are an essential part of Sennett's contemporary craft worker's persona, as explored above; and they are vital to the hairdresser. Like Sennett's surgeon and scalpel, or conductor and baton, the hairdresser has a key tool; it is their pair of scissors. Just as Sennett describes, there is a synthesis between worker and tool. When cutting hair the scissors become an extension of the hairdresser's body; they are as important as the fingers (Farleigh, 1939). Using 'virtuoso skills' (Becker, 1978: 865), working with speed and agility to do something others would find difficult, the hairdresser adeptly navigates the scissors through the hair. Creative methodologies, such as photographs, help to capture the minutiae of practice (Harris, 2011), aided by the thick description of skill Hampson and Junor (2005) request. Just as Erin O'Connor (2007: 131) successfully combines both to attend to the corporeal practice of glass blowing, so the following aims to illuminate the 'lived experience of craft'.

Figures 1 to 3 depict the cutting process. Initially the hair is divided into sections. Taking one of the sections, the hairdresser begins working from one end of the section to the other. She combs through the hair, moving the scissors into the crook of her right hand as she does so. Stopping where she wants to cut, she places two fingers where the 


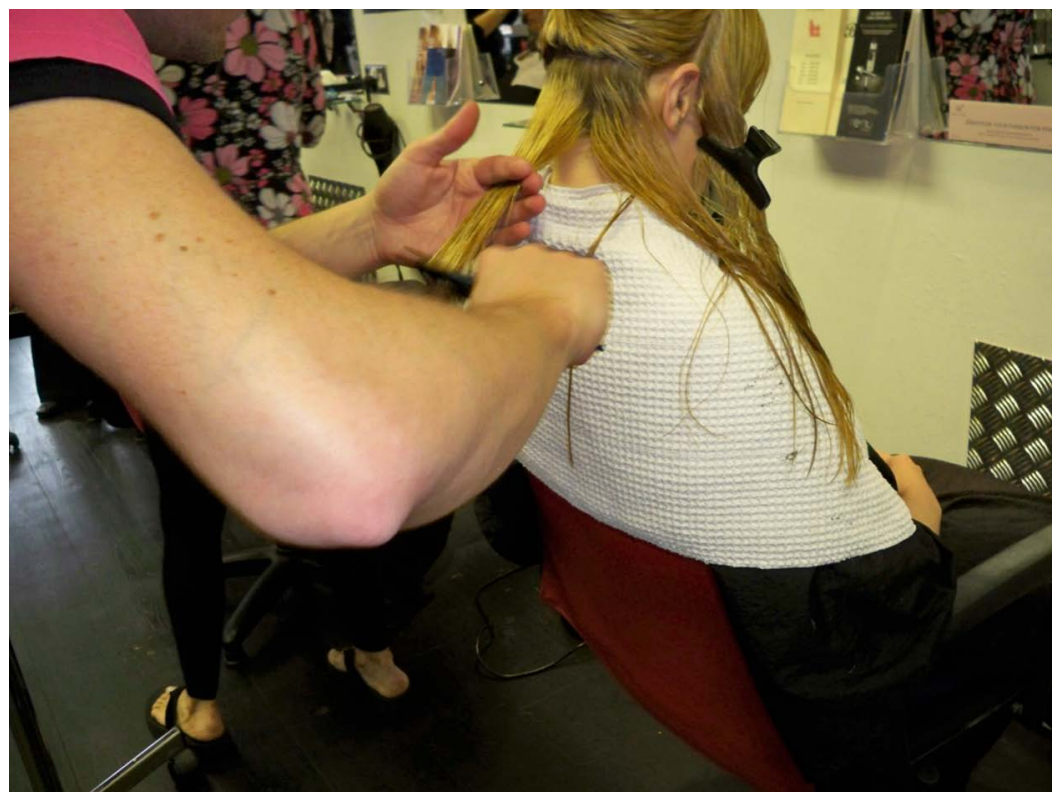

Figure I. The cutting process - hair is divided into sections.

comb was, while simultaneously moving the comb out of the way to sit between the left thumb and forefinger. Swiftly moving the scissors into prime position, holding with the right thumb and first two fingers, she begins to cut from left to right. This sequence is repeated over and over until the section of hair has all been trimmed. It then begins again as another section of hair is let down. The smooth rapidity of this routine, repeated sometimes hundreds of times on one person's head within a matter of minutes, is incredible. The hairdresser and scissors are one.

As Anna Harris (2011: 313) discusses with reference to doctors and their use of tools, the worker only becomes aware of 'the contours of the situation' and the distance which separates them from it and the object worked upon, when the 'script' of the tool is not followed. Indeed, the only occasion where the divide between object and self becomes apparent is when the hairdresser catches their other hand holding the hair or when, as described below, the hairdresser senses their scissors have been used by another:

Helen: The thing that amazed me, you know when you told me about how everyone holds their scissors differently and how you all know if someone else has had them and I can't quite get my head round that.

Parr: $\quad$ You use different parts of the blade

Patricia: You know my new ones?

Parr: $\quad \mathrm{Hmmm}$

Patricia: Someone has had them and they're fucked them now.

Alana: Someone's being cutting card or something with them [giggling from others]. 


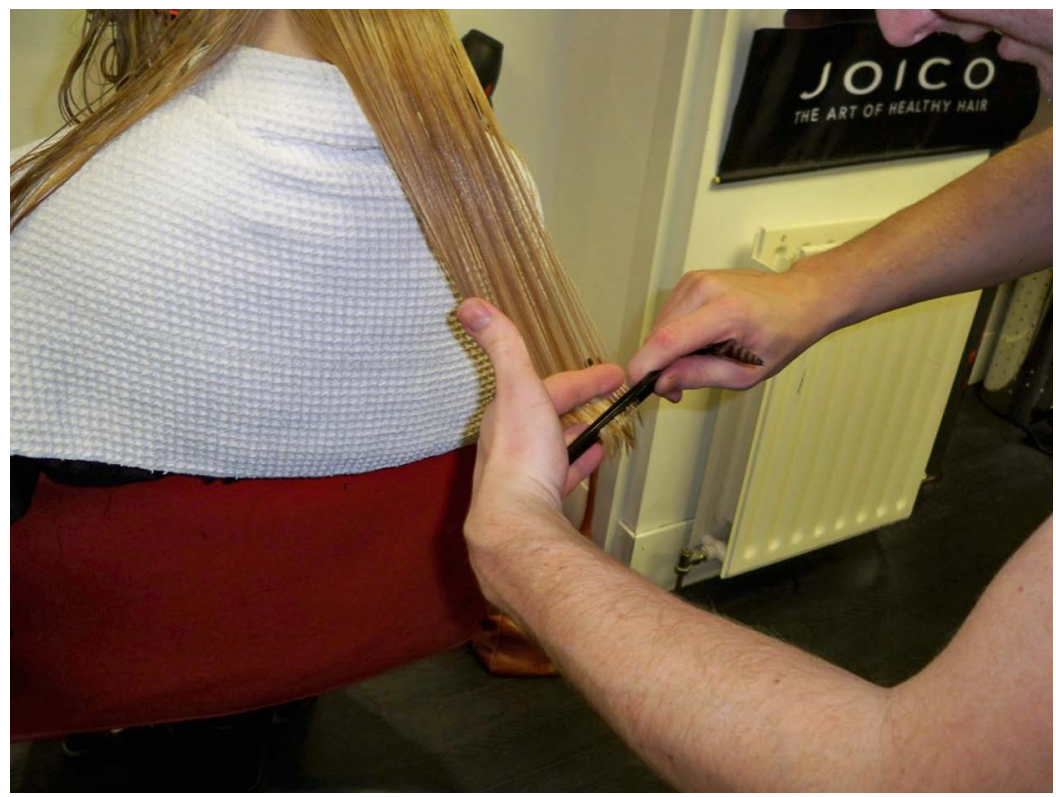

Figure 2. The cutting process continued - The section of hair is combed and held between the thumb and first two fingers of the left hand.

Helen: How do you know though?

Alana: Cos you can feel.

Patricia: You just do.

There is no way of telling by looking at the scissors if they have been used by someone else. It is only through the intricacies of practice, utilizing embodied and sensory proximal knowledge (Hetherington, 2003) that, as stylist Alana emphasizes, 'you can feel' the difference. Just by using the scissors the hairdresser knows instantly if they have been tampered with, changing the way they can use them and the effect they have on hair. A hairdresser's scissors, like a surgeon's scalpel or the file of a goldsmith, can be understood as creating a cathexis; forming an unmistakable, emotional bond with an object that links them to the world (Attfield, 2000). Without this tool, the craftsperson cannot perform their job; it is a fundamental part of what makes them a hairdresser, a surgeon, a goldsmith and above all a craft worker.

Yet, the scissors are not the only tool used by the hairdresser. As the above description of the cutting process illustrates, the hairdresser must synchronize their scissors with the comb. Sennett highlights how the craftsman has an array of tools, knowing how each one is 'fit for purpose'; and so too hairdressers, in their 'rhythm of routine', unite tool with skill. Hairdryers, foil, clips, brushes, dyes, rollers, straighteners and numerous other tools all play their part within specific practices. The hairdresser must know not just how and when to use each tool, but also how to co-ordinate tools to work together. Like the scissors and comb during the cutting process, the hairdryer and brush must work in 


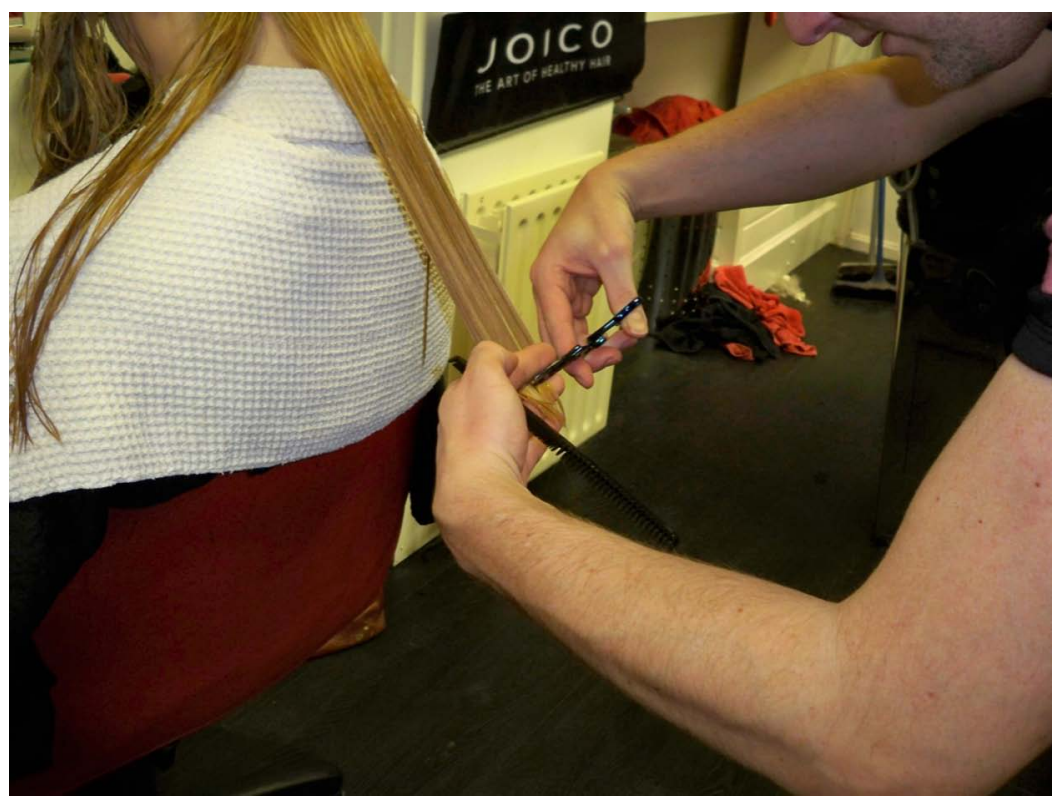

Figure 3. The cutting process continued - The comb is moved to the left hand, scissors into the right and the hair is cut.

tandem during the styling process. As the brush is pulled underneath a section of hair, so the hairdryer follows it over the top to dry it off. When the brush reaches the end of the section of hair it is quickly substituted by the barrel of the hairdryer to hold the hair in place, while the brush is moved swiftly back to the top of the hair shaft to begin the movement again. Thus, alliances and dependencies form between the tools, being teased out by the hairdresser through craft practice (Bijker, 1992; Hand and Shove, 2007; Shove et al., 2007). The hairdresser must discipline their body into set positions to ensure that body and tools work together and the practice is done correctly.

It is at this juncture, of body and tools fusing through craft practice, that the focus upon practice must take a different turn. So far, this article has illustrated how approaching service work through the lens of practice enables often tacit and intangible skills to be valued as craft. But what about the materials they craft? In Sennett's reading, craft practice is only fully explored in those cases where end-objects/products are fixed, stable and durable. But craft-produced objects, like craft practices, can be unstable, temporary and often intangible. This article contends that it is the instability of objects and materials produced through service work which perpetuates the invisibility of the practices and skills used to create them and, as a result, this is one key way in which service work remains undervalued. Once again hair and the hairdresser illustrate this point.

\section{Transient craft}

Hair is always 'coming-into-being' (Ingold, 2000: 57). Despite being located at what have been termed 'the dead margins of the body' (Kwint, 1999: 9), it is a substance 
which was regularly described by the focus group participants as 'having a life of its own'. It grows, it splits, snaps, gets greasy, goes grey - hair is always changing. Or, as Chris Shilling (1993: 24) describes, hair, like the rest of the body, is always in the process of 'becoming'. Unlike the Barolo goblet of Sennett's glassmaker or the pristine new piano of the piano maker, hair is not a durable, fixed product, but requires repeated crafting. Ironically, while hairdressers are often portrayed as giving hair life, cultivating 'body', 'shine' and 'hair-swishing' energy, their primary task is in fact the opposite. Their role is to control and still hair's vitality.

Nevertheless, such control is only fleeting. Through the synthesis of tools and craft practice hair's vitality is temporarily stilled. The scissors have cut away the hair. The tools - hairdryers, brushes, sprays, clips - combined with the hairdresser's skill have moulded and shaped the hair. All of which culminates in the final moment of hair's craft production, what I have termed 'the final reveal'. Often accompanied with the words 'Is that okay for you?' the hairdresser uses a handheld mirror to show the customer the back of their hair; their reflection doubled as the image in the handheld mirror is subsequently reflected in that facing the customer. In that moment the self is stabilized, one's identity appears fixed and coherent (Mol and Law, 2004: 56). Yet 'the final reveal' is transitory, hair's vitality never truly stilled. As soon as the customer leaves the salon, the rhythm of hair's vitality begins again. Within a matter of time it becomes greasy, colours fade and grey shows through. And, of course, it grows: styles become softer, less shaped; fringes get in the way of seeing; roots and split ends become apparent. Unlike the mark of the medieval craftsman, a stamp on a brick or a workshop crest on a piece of pottery, the signature of the hairdresser is transitory, unstable and, after some time, seemingly intangible. Hairdressers' labour and skill are not stored indefinitely in the materials they craft (Steedman, 2007; Stewart, 1999), but rather ebbs away over time, as hair grows and changes.

However fleeting though, the work of the hairdresser is always bespoke; just like the Barolo goblet or the Stradivari violin. As focus group participant Heather, a former hairdresser describes, crafting hair is 'like somebody's handwriting, everybody is different.' Just as hairdressers hold their scissors differently, being able to feel when someone else has used them, so they each make their own unique mark upon the head of hair. What is more, each visit to the hairdresser is itself a unique event. While colours may be repeated or styles trimmed by the same hairdresser on repeat visits, because of the vitality of hair each visit produces a new bespoke product. The craft of hair is always on-going.

\section{Conclusions}

The example of the hairdresser illuminates how service work as craft work can involve the production of something transitory, or unstable. For the hairdresser, craft work is stabilized in the moment of revelation, the fleeting instant when hair is temporarily stilled. It is the transitory nature of the body 'always becoming' which guarantees its repetitive crafting. Therefore, craft work may occur at the hands of the hairdresser, the dentist, the beautician or any other profession which engages in work upon the body. Such work may produce tangible results, which change over time, a new haircut or waxed hair-free legs. Others may be much less tangible, for example the efforts made by a care worker to ensure a client is kept clean and comfortable, or a nurse ensuring that a 
patient's drip is working correctly, or that the correct medication is given. These all require practised skill; and skills which are all too often ignored or undervalued.

Appreciating that craft can be transitory and unstable also opens it up to other forms of work not involving the ever changing body. Professions such as cleaning, gardening and cooking are all examples where repetitive skilled practice takes place, yet the fruits of that labour are held fleetingly in material form. This is not to argue that anyone who engages in cleaning, gardening or cooking is a master craft worker. As the example of the hairdresser has illustrated, there is a demarcation between the amateur and the professional based fundamentally on experience, practice and skill set.

Nor is it to argue that these service roles require only practical skills. This article has deliberately steered away from an emphasis on the emotional aspects of service work, largely because they have a tendency to overshadow other skills involved in service work, such as the cognitive, technical and organizational (Hampson and Junor, 2005). By extending to service work Sennett's (2008) practice-based approach to employment, this article has drawn out the practical, hands-on skills which such work involves; skills which cannot be taught but can only be learnt through experience and practice. This is by no means to contend that emotion work, body work and aesthetic labour are not part of the craft of particular forms of service work. They too, like the practical skills explored here, can be integral to craft and are also honed through experience. Nonetheless, the crux of the argument is that craft work occurs in occupations traditionally determined as lacking in skill and expertise and producing 'products' (objects, materials or bodies) of inconsequential value. By laying bare these intangible practices and the unstable goods created, this article reveals the expertise required to perform and produce them and, thus, goes some distance in arguing for the recognition and remuneration of such feminized service roles. In so doing, it facilitates a move away from historically entrenched understandings of craft and narrow object-centred studies, to a much more flexible, inclusive concept of craft; a concept which can and does involve service-based, low skilled and female-dominated professions, such as hairdressing.

\section{Acknowledgements}

Many thanks to Nicky Gregson, Durham University, for her invaluable help and comments.

\section{Funding}

This research was funded by an ESRC Postgraduate Studentship Award (PTA-031-2006-00255).

\section{References}

Attfield J (2000) Wild Things: The Material Culture of Everyday Life. London: Berg. Becker HS (1978) Arts and crafts. American Journal of Sociology 83(4): 862-89.

Berry S (2009) From peasant to artisan: motor mechanics in a Nigerian town. In: Adamson G (ed.) The Craft Reader. London: Berg, 263-71.

Bijker WE (1992) The social construction of fluorescent lighting, or how an artifact was invented in its diffusion stage. In: Bijker WE and Law J (eds) Shaping Technology/Building Society: Studies in Sociotechnical Change. Cambridge, MA: Massachusetts Institute of Technology, 75-104. 
Blewett MH (1983) Work, gender and the artisan tradition in New England shoemaking 1780 1860. Journal of Social History 17(2): 221-48.

Bolton SC (2009) Getting to the heart of the emotional labour process: a reply to Brook. Work, Employment and Society 23(3): 549-60.

Bolton SC and Boyd C (2003) Trolley dolly or skilled emotion manager? Moving on from Hochschild's Managed Heart. Work, Employment and Society 17(2): 289-308.

Braverman H (1974) Labor and Monopoly Capital: The Degradation of Work in the Twentieth Century. New York, NY: Monthly Review Press.

Callaghan G and Thompson P (2002) 'We recruit attitude': the selection and shaping of call centre labour. Journal of Management Studies 39(2): 233-54.

Camp CW (1924) The Artisan in Elizabethan Literature. New York, NY: Columbia University Press.

Campbell C (2005) The craft consumer: culture, craft and consumption in postmodern society. Journal of Consumer Culture 5(1): 23-42.

Chugh S and Hancock P (2009) Networks of aestheticization: the architecture, artefacts and embodiment of hairdressing. Work, Employment and Society 23(3): 460-76.

Clarke L, Winch C and Brockmann M (2013) Trade-based skills versus occupational capacity: the example of bricklaying in Europe. Work, Employment and Society 27(6): 932-51.

Cohen RL (2010) When it pays to be friendly: employment relationships and emotional labour in hairstyling. Sociological Review 58(2): 197-218.

Crossick G (1997) Past masters: in search of the artisan in European history. In: Crossick G (ed.) The Artisan and the European Town 1500-1900. London: Ashgate, 1-40.

Dormer P (1997) The Culture of Craft. Manchester: Manchester University Press.

Entwistle J (2002) The aesthetic economy: the production of value in the field of fashion modelling. Journal of Consumption Culture 2(3): 317-39.

Fariello AM and Owen P (2005) Objects and Meaning: New Perspectives on Art and Craft. Lanham, MD: Scarecrow Press.

Farleigh J (1939) The Creative Craftsman. London: G. Bell and Sons.

Gatta M (2009) Balancing trays and smiles: what restaurant servers teach us about hard work in the service economy. In: Bolton S and Houlihan M (eds) Work Matters: Critical Reflections on Contemporary Work. Basingstoke: Palgrave Macmillan, 114-28.

Gatta M, Boushey H and Appelbaum E (2009) High touch and here-to-stay: future skills demands in US low wage service occupations. Sociology 43(5): 968-89.

Gimlin D (1996) Pamela's place: power and negotiation in the hair salon. Gender and Society 10(5): 505-26.

Greenhalgh P (2002) Introduction: craft in a changing world. In: Greenhalgh P (ed.) The Persistence of Craft. London: A and C Black, 1-16.

Griffin C (1985) Typical Girls: Young Women from School to the Job Market. London: Routledge.

Habia (2007) Skills Survey of the Hairdressing Industry. March 2008. Available (consulted 7 May 2014) at: http://www.habia.org/

Halford S, Savage M and Witz A (1997) Gender, Careers and Organisations: Current Developments in Banking, Nursing and Local Government. Basingstoke: Palgrave Macmillan.

Hall E (1993) Smiling, deferring and flirting: doing gender by giving 'Good Service'. Work and Occupations 20(4): 452-71.

Hampson I and Junor A (2005) Invisible work, invisible skills: interactive customer service as articulation work. New Technology, Work and Employment 20(2): 166-81.

Hand M and Shove E (2007) Condensing practices: ways of living with a freezer. Journal of Consumer Culture 7(1): 79-104. 
Harris A (2011) In a moment of mismatch: overseas doctors' adjustments in new hospital environments. Sociology of Health and Illness 33(2): 308-20.

Hetherington K (2003) Spatial textures: place, touch and praesentia. Environment and Planning A 35(11): 1933-44.

Hochschild AR (1983) The Managed Heart: Commercialization of Human Feeling. London: University of California Press.

Holliday R (2001) 'We've been framed!' Visualizing methodology. Sociological Review 48(4): $503-22$.

Ingold T (2000) Making culture and weaving in the world. In: Graves-Brown PM (ed.) Matter, Materiality and Modern Culture. London: Routledge, 50-71.

Junor A, Hampson I and Ogle KR (2009) Vocabularies of skill: the case of care and support workers. In: Bolton S and Houlihan M (eds) Work Matters: Critical Reflections on Contemporary Work. Basingstoke: Palgrave Macmillan, 197-215.

Kapp Howe L (1977) Pink Collar Workers: Inside the World of Women's Work. New York, NY: Avon Books.

Kwint M (1999) Introduction. In: Kwint M et al. (eds) Material Memories. Oxford: Berg, 1-16.

Lee-Treweek G (1997) Women, resistance and care: an ethnographic study of nursing auxiliary work. Work, Employment and Society 11(1): 47-63.

Levine F and Heimerl C (2008) Handmade Nation: The Rise of DIY, Art, Craft, and Design. Princeton, NJ: Princeton Architectural Press.

Lindsay J (2004) Gender and class in the lives of young hairdressers: from serious to spectacular. Journal of Youth Studies 7(3): 259-77.

Lloyd C and Payne J (2009) 'Full of sound and fury, signifying nothing': interrogating new skill concepts in service work - the view from two UK call centres. Work, Employment and Society 23(4): 617-34.

McDowell L (2009) Working Bodies: Interactive Service Employment and Workplace Identities. Oxford: Wiley-Blackwell.

McDowell L and Pringle R (1992) Defining Women: Social Institutions and Gender Divisions. Oxford: Wiley-Blackwell.

Minahan S and Wolfram-Cox J (2007) Stitch 'n' bitch: cyberfeminism, a third place and the new materiality. Journal of Material Culture 12(1): 5-21.

Mol A and Law J (2004) Embodied action, enacted bodies. Body and Society 10(2/3): 43-62.

O'Connor E (2007) Embodied knowledge in glassblowing: the experience of meaning and the struggle towards proficiency. Sociological Review 55(s1): 127-41.

Oerton S (2004) Bodywork boundaries: power, politics and professionalism in therapeutic massage. Gender, Work and Organization 11(5): 544-63.

Payne J (2009) Emotional labour and skill: a reappraisal. Gender, Work and Organization 16(3): $348-67$.

Pettinger L (2006) On the materiality of service work. Sociological Review 54(1): 48-67.

Pink S (2001) Doing Visual Ethnography: Images, Media and Representation in Research. London: SAGE.

Reckwitz A (2002) Toward a theory of social practices: a development in culturalist theorising. European Journal of Social Theory 5(2): 245-65.

Ritzer G (1996) The McDonaldization of Society. London: SAGE.

Sanders T (2005) Sex Work: A Risky Business. Cullompton: Willan Publishing.

Schatzki T (2002) The Site of the Social: A Philosophical Account of the Constitution of Social Life and Change. University Park, PA: Pennsylvania State University Press.

Sennett R (2008) The Craftsman. London: Penguin Books.

Shilling C (1993) The Body and Social Theory. London: SAGE. 
Shove E (2003) Comfort, Cleanliness and Convenience: The Social Organisation of Normality. London: Berg.

Shove E, Hand M and Watson M (2007) The Design of Everyday Life. Oxford: Berg.

Steedman C (2007) Master and Servant: Love and Labour in the English Industrial Age. Cambridge: Cambridge University Press.

Stewart S (1999) Prologue: from the museum of touch. In: Kwint M et al. (eds) Material Memories. Oxford: Berg, 17-36.

Terrio S (2000) Crafting the Culture and History of French Chocolate. Berkeley, CA: University of California Press.

Toerien M and Kitzinger C (2007) Emotional labour in action: navigating multiple movements in the beauty salon. Sociology 41(4): 645-62.

Twigg J (2000) Carework as a form of bodywork. Ageing and Society 20(4): 389-411.

Twigg J, Wolkowitz C, Cohen RL and Nettleton S (2011) Conceptualising body work in health and social care. Sociology of Health and Illness 33(2): 171-88.

Tyler M and Abbott P (1998) Chocs away: weight watching in the contemporary airline industry. Sociology 32(3): 430-50.

Wacquant LJD (1995) The pugilistic point of view: how boxers think and feel about their trade. Theory and Society 24(4): 489-535.

Witz A, Warhurst C and Nickson D (2003) The labour of aesthetics and the aesthetics of organization. Organization 10(1): 33-54.

Wolkowitz C (2002) The social relations of body work. Work, Employment and Society 16(3): 497-510.

Yeadon-Lee T, Jewson N, Felstead A, Fuller A and Unwin L (2011) Bringing in the customers: regulation, discretion and customer service narratives in upmarket hair salons. International Journal of Interdisciplinary Social Sciences 6(3): 101-14.

Helen Holmes is a Research Associate at the University of Sheffield currently working as an embedded ethnographer on the interdisciplinary project Solar Energy for Future Societies.

Date submitted January 2013

Date accepted April 2014 